\title{
The effects of 2,3-diphosphoglycerate, adenosine triphosphate, and glycosylated hemoglobin on the hemoglobin-oxygen affinity of diabetic patients
}

E.M. Castilho ${ }^{1}$,

M.L. Glass ${ }^{1}$ and

J.C. Manço ${ }^{2}$
Correspondence

M.L. Glass

Departamento de Fisiologia

FMRP, USP

Av. Bandeirantes, 3900

14049-900 Ribeirão Preto, SP

Brasil

Fax: +55-16-633-0017

E-mail:mlglass@rfi.fmrp.usp.br

Publication supported by FAPESP

Publicen

Received August 29, 2002

Accepted February 11, 2003

\author{
${ }^{1}$ Departamento de Fisiologia, Faculdade de Medicina de Ribeirão Preto, \\ Universidade de São Paulo, Ribeirão Preto, SP, Brasil \\ ${ }^{2}$ Laboratório de Pneumologia, Departamento de Clínica Médica, \\ Hospital das Clínicas, Faculdade de Medicina de Ribeirão Preto, \\ Universidade de São Paulo, Ribeirão Preto, SP, Brasil
}

\begin{abstract}
The position of the oxygen dissociation curve (ODC) is modulated by 2,3-diphosphoglycerate (2,3-DPG). Decreases in 2,3-DPG concentration within the red cell shift the curve to the left, whereas increases in concentration cause a shift to the right of the ODC. Some earlier studies on diabetic patients have reported that insulin treatment may reduce the red cell concentrations of 2,3-DPG, causing a shift of the ODC to the left, but the reports are contradictory. Three groups were compared in the present study: 1) nondiabetic control individuals ( $\mathrm{N}=$ 19); 2) insulin-dependent diabetes mellitus (IDDM) patients (on insulin treatment) $(\mathrm{N}=19) ; 3)$ non-insulin-dependent diabetes mellitus (NIDDM) patients using oral hypoglycemic agents and no insulin treatment $(\mathrm{N}=22)$. The overall position of the ODC was the same for the three groups despite an increase of the glycosylated hemoglobin fraction that was expected to shift the ODC to the left in both groups of diabetic patients $\left(\mathrm{HbA}_{1 \mathrm{c}}\right.$ : control, 4.6\%; IDDM, $10.5 \%$; NIDDM, $9.0 \%$ ). In IDDM patients, the effect of the glycosylated hemoglobin fraction on the position of the ODC appeared to be counterbalanced by small though statistically significant increases in 2,3-DPG concentration from 2.05 (control) to $2.45 \mu \mathrm{mol} / \mathrm{ml}$ blood (IDDM). Though not statistically significant, an increase of 2,3-DPG also occurred in NIDDM patients, while red cell ATP levels were the same for all groups. The positions of the ODC were the same for control subjects, IDDM and NIDDM patients. Thus, the $\mathrm{PO}_{2}$ at $50 \%$ hemoglobinoxygen saturation was $26.8,28.2$ and $28.5 \mathrm{mmHg}$ for control, IDDM and NIDDM, respectively. In conclusion, our data question the idea of adverse side effects of insulin treatment on oxygen transport. In other words, the shift to the left reported by others to be caused by insulin treatment was not detected.
\end{abstract}

Key words

- Oxygen delivery

- Diabetes mellitus

- Oxygen dissociation curve

- 2,3-Diphosphoglycerate

- IDDM

- NIDDM

- Glycosylated hemoglobin 


\section{Introduction}

In a pioneering study, Benesch and Benesch (1) found that 2,3-diphosphoglycerate (2,3-DPG) keeps the oxygen dissociation curve (ODC) within its normal operational range. An increase of 2,3-DPG reduces hemoglobin-oxygen $\left(\mathrm{HbO}_{2}\right)$ affinity, i.e., causes a shift to the right of the ODC, and increases the cooperativity of the four hemoglobin chains. On the other hand, decreased levels of 2,3-DPG cause a shift to the left and reduce cooperativity.

Red cell 2,3-DPG levels may counteract the effects of blood acid-base status on the $\operatorname{ODC}(2,3)$. For example, acute high altitude hypoxia combined with hyperventilation-induced alkalosis shifts the ODC to the left. An increase of red cell 2,3-DPG may, however, oppose this effect and return the ODC to its normal position (4). Modulations of 2,3DPG concentrations may also occur during lack of oxygen due to congenital cardiac problems, anemia and chronically reduced cardiac output. Under these circumstances, 2,3-DPG concentrations increase with a consequent shift to the right of the ODC (for a review, see Ref. 5). The concomitant intracellular alterations have been examined in a large number of studies. Within the red cell, the glycolytic pathway includes the transformation steps from glucose to lactate. An intermediate step consists of the transformation of fructose-6-phosphate to 1,3-DPG. As a specific feature, the red cell has a shunt in which 2,3-DPG is formed from 1,3-DPG, involving a diphosphoglycerate mutase. Acidosis acts on this step to reduce 2,3-DPG formation and, moreover, depresses the main pathway in an anterior phosphofructokinasemediated transformation step (5). Ketoacidosis ( $\mathrm{pH}<7.1$ ) in insulin-dependent diabetes mellitus (IDDM) can be associated with considerable reductions of 2,3-DPG levels (2,6-10), which partly compensate for the acid-induced shift to the right of the curve. Data for diabetic patients without ketoacido- sis are, however, inconsistent. Thus, it has been reported that insulin administration decreases plasma concentrations of inorganic phosphates, leading to a reduced production of 2,3-DPG (11). Reduced levels of 2,3DPG increase $\mathrm{HbO}_{2}$ affinity, which, predictably, reduces oxygen delivery to the tissues $(12,13)$. Farber et al. (13) induced diabetes in rats and subsequently measured 2,3-DPG levels and quantified the extent of nerve tissue degeneration. They found degeneration only in insulin-treated rats with lowered combined levels of 2,3-DPG and ATP. However, in a clinical study, Bodnar and Pristupiuk (14) reported a significant increase in 2,3-DPG in diabetic patients when compared to nondiabetic subjects.

In diabetes mellitus an increased glycosylation of hemoglobin tends to shift the ODC to the left, which would reduce oxygen delivery to tissues $(15,16)$. Concomitantly, elevated levels of 2,3-DPG could shift the ODC to the right, which would then recover its normal position (17-19). Story et al. (20) concluded, however, that the increases of erythrocyte 2,3-DPG concentrations were insufficient to compensate for the formation of glycosylated hemoglobin $\left(\mathrm{HbA}_{1 \mathrm{c}}\right)$ and to maintain normal $\mathrm{HbO}_{2}$ affinity in IDDM patients. By contrast, studying streptozotocin-induced diabetic rats, Alder et al. (21) observed that $\mathrm{HbA}_{1 \mathrm{c}}$ formation was counterbalanced by elevated 2,3-DPG. As a further complication, Kihara et al. (22) reported that the position of the ODC and the concentration of red cell 2,3-DPG of insulin-treated rats did not suffer any physiologically significant changes of the ODC or levels of 2,3DPG. On the other hand, insulin treatment reduced tissue perfusion and nutrient supply to nerve tissue.

Considering these contradictory data, we decided to re-examine a possible influence of diabetes on red cell concentrations of 2,3DPG, ATP and $\mathrm{HbA}_{1 \mathrm{c}}$. In addition, the position of the ODC was determined. These measurements were performed in nondia- 
betic individuals and in non-insulin-dependent diabetes mellitus (NIDDM) and IDDM patients by applying standard selection criteria $(6,23-26)$. The paper focuses on the possible specific consequences of insulin treatment on 2,3-DPG levels and on the position of the ODC. As a special precaution, we have used a firmly established method to construct the ODC (see Methods). In addition, the curves were constructed based on several saturation points for $\mathrm{PO}_{2} / \mathrm{O}_{2}$-saturation relationships. In short, we based our study on multiple curve points combined with high n-values for each point.

\section{Material and Methods}

A total of 60 individuals were studied, divided into three groups: 1) nondiabetic individuals $(\mathrm{N}=19,12$ males and 7 females; mean age \pm SEM: $34.7 \pm 0.4$ years; range: 23 to 52 years); 2) $\operatorname{IDDM}(\mathrm{N}=19,10$ males and 9 females; mean age \pm SEM: $31.5 \pm 1.0$ years; range: 14 to 59 years); 3) NIDDM $(\mathrm{N}=22,8$ males and 14 females; mean age \pm SEM: $52 \pm 0.6$ years; range: 30 to 70 years). Individuals with renal disturbances, smokers, alcohol-dependent persons and also individuals using medication for any disease other than diabetes were excluded from the study. Patients were recruited at the Diabetes Outpatient Clinic, Division of Endocrinology and Metabolism, Department of Clinical Medicine, University Hospital, Faculty of Medicine of Ribeirão Preto, University of São Paulo (FMRP-USP), Ribeirão Preto, SP, Brazil. The study was approved by the Ethics Committee of the University Hospital, FMRP-USP, and all samples were obtained with informed consent from all patients.

\section{Blood samples}

In the early morning hours, heparinized venous blood $(17 \mathrm{ml})$ was withdrawn from fasting and resting patients and control individuals. The samples were immediately ana- lyzed for in vivo $\mathrm{pH}, \mathrm{PCO}_{2}, \mathrm{PO}_{2}$ and $\mathrm{HbO}_{2}$ saturation using a Corning model 178 blood gas analyzer (Corning Inc., New York, NY, USA). Hematocrit and hemoglobin concentrations were then determined with a model T-890 Coulter (Beckman Coulter International, Nyon, Switzerland). In order to exclude individuals with abnormal hemoglobin, electrophoresis was carried out according to the method of Marengo-Rowe (27). In addition, $50 \mu \mathrm{l}$ of fresh blood was hemolyzed to assess $\mathrm{HbA}_{1 \mathrm{c}}$. Part of the blood was stored on dry ice and analyzed for ATP and 2,3-DPG within 15 min after withdrawal. In addition, tonometry for ODC construction was initiated within 10 min after sampling. Blood for the determination of glucose levels was withdrawn into a vacuum tube containing EDTA (Vacutainer, Franklin Lakes, NJ, USA).

\section{Construction of the oxygen dissociation curve}

The ODC was constructed on the basis of the "blood mixing technique" $(28,29)$. In this procedure, the blood sample is divided into two equal volumes, each placed inside a tonometer. One tonometer was equilibrated with a gas mixture of $30 \% \mathrm{O}_{2}, 6 \% \mathrm{CO}_{2}$ and balance $\mathrm{N}_{2}$, which assures maximal saturation. The other tonometer received a mixture of $0 \% \mathrm{O}_{2}, 6 \% \mathrm{CO}_{2}$ and balance $\mathrm{N}_{2}$ to deoxygenize the blood. In both tonometers $\mathrm{CO}_{2}$ was kept constant at $6 \%$, corresponding closely to $40 \mathrm{mmHg}$ at the altitude of FMRPUSP. Equilibration of the blood with these gas mixtures was achieved within $30 \mathrm{~min}$, after which a 1-ml Hamilton syringe was used to withdraw known fractions of saturated and desaturated blood to obtain several saturations $(20,30,50,70$, and 80\%). Mercury was used not only to clear the syringe dead space but also to mix the blood samples within the syringe. The mixed blood volume (1 ml total) was then analyzed for $\mathrm{PO}_{2}, \mathrm{PCO}_{2}$, $\mathrm{pH}$ and $\mathrm{HbO}_{2}$ saturation, using a blood gas analyzer (Corning model 178). 
The curves are reported using the classical Hill plot, which is a logarithmic approach that permits the best possible definition of the position of the curve, since linear regression analysis can be applied.

Table 1. Relationships between hemoglobin-oxygen $\left(\mathrm{HbO}_{2}\right)$ saturation and partial oxygen pressure $\left(\mathrm{PO}_{2}\right)$ for the three groups studied.

\begin{tabular}{lccc}
\hline $\mathrm{HbO}_{2}$ saturation (\%) & \multicolumn{3}{c}{$\mathrm{PO}_{2}(\mathrm{mmHg})$} \\
\cline { 2 - 4 } & Control (N = 19) & IDDM (N = 19) & NIDDM (N = 22) \\
\hline 20 & $16.2 \pm 0.4$ & $16.9 \pm 0.4$ & $16.9 \pm 0.4$ \\
30 & $19.5 \pm 0.4$ & $20.3 \pm 0.4$ & $20.6 \pm 0.3$ \\
50 & $26.8 \pm 0.6$ & $28.2 \pm 0.5$ & $28.5 \pm 0.3$ \\
70 & $38.2 \pm 0.5$ & $38.8 \pm 0.6$ & $38.9 \pm 0.4$ \\
80 & $46.8 \pm 0.9$ & $47.6 \pm 3.6$ & $47.9 \pm 0.6$ \\
\hline
\end{tabular}

Data are reported as means \pm SEM.

IDDM, insulin-dependent diabetes mellitus; NIDDM, non-insulin-dependent diabetes mellitus.

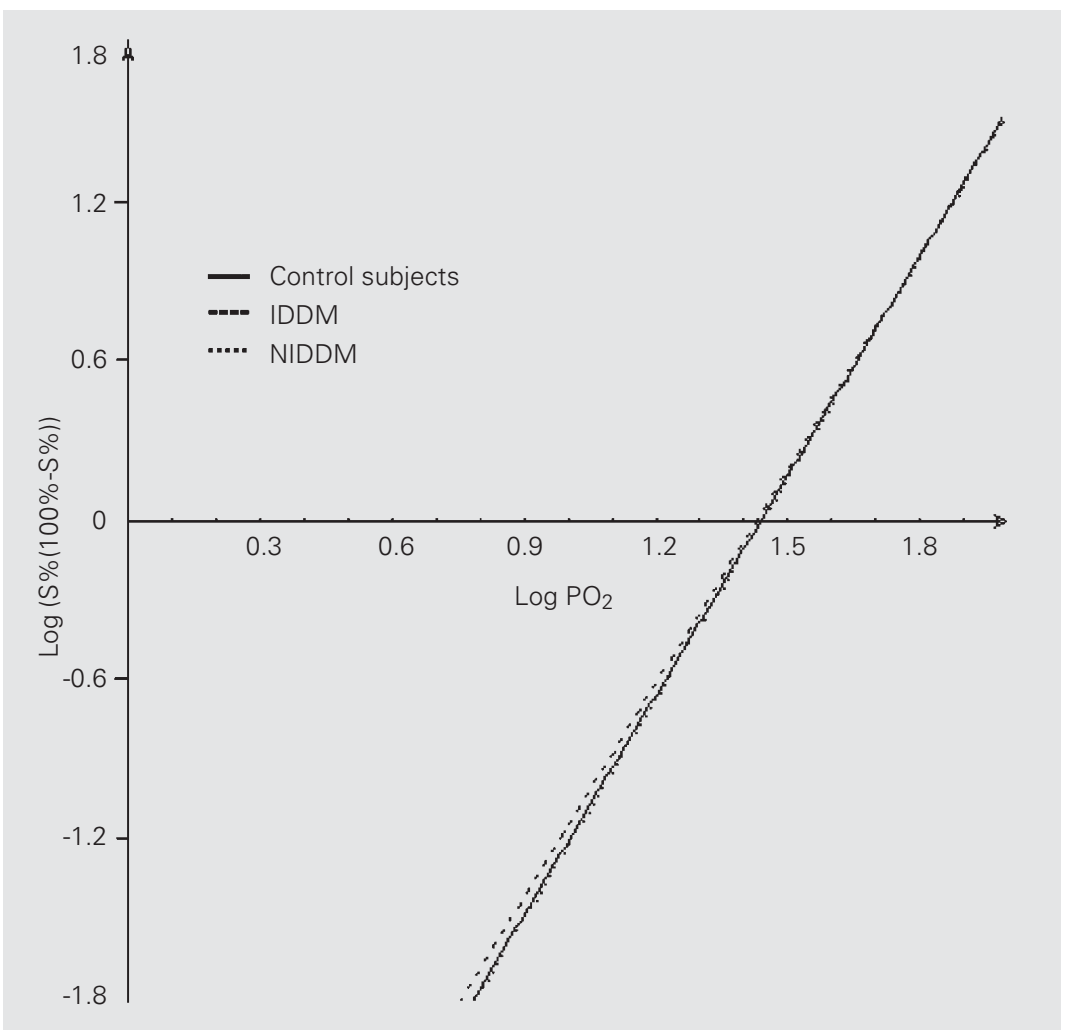

Figure 1. Hill plots for the oxygen dissociation curves for the three groups. See Table 2. IDDM, insulin-dependent diabetes mellitus; NIDDM, non-insulin-dependent diabetes mellitus.
Analysis of glucose, 2,3-DPG, $\mathrm{HbA}_{1 \mathrm{c}}$ and ATP

Glucose levels were determined using a Sera-Pak diagnostic kit (Sera-Pak, Bayer Corp., New York, NY, USA) based on the method of Trinder (30). According to standard procedures for evaluation of diabetes mellitus, the $\mathrm{HbA}_{1 \mathrm{c}}$ fraction (\%) was measured using a diagnostic kit (Glyco-Test II, Pierce, Rockford, IL, USA). Concentrations of 2,3-DPG were determined with a $35 \mathrm{UV}$ kit (Sigma, St. Louis, MO, USA) according to the method of Lowry et al. (31), modified by Rose and Liebowitz (32). ATP concentrations were determined using a Sigma 366 UV kit $(33,34)$.

\section{Statistical analysis}

Data are reported as means \pm SEM (see n-values above). Analysis of variance (ANOVA) was performed and the Tukey or Student $t$-test was applied to determine the level of statistical difference between individual groups. Values of $\mathrm{P}<0.05$ were considered to be significant.

The Pearson test for linear regression was used to analyze Hill plots in relation to correlation coefficient and $95 \%$ confidence intervals for the intercept of the regression line with the $\mathrm{Y}$-axis.

\section{Results}

The $\mathrm{PO}_{2}$-saturation relationships were identical for the three groups (see Table 1). The ODC are presented as Hill plots in Figure 1 , that compares control individuals to IDDM and NIDDM patients. To perform a statistical analysis, the data of Table 1 were transformed into the form of Hill plots. The overlap of $95 \%$ confidence intervals for the groups (control, IDDM and NIDDM) implies that the overall curves were not statistically different. The constants and statistics for the Hill plots are presented in Table 2. The position of the ODC was not significant- 
ly different between groups.

The acid-base status of venous blood samples was different for the three groups. Both groups of patients had a reduced $\mathrm{pH}$ relative to the control group, and the lowest in vivo values were measured in IDDM patients, while the reduction of the NIDDM group was not significantly different from control (Table 3). Consistently, venous $\mathrm{PCO}_{2}$ was slightly elevated in both groups of diabetic patients, but was not statistically different from control (Table 3). During in vitro tonometry with $6 \% \mathrm{CO}_{2}$ (identical $\mathrm{CO}_{2} \%$ and $\mathrm{PCO}_{2}$ ) the blood $\mathrm{pH}$ values became statistically identical when equilibrated at the same $\mathrm{PCO}_{2}$ (control 7.40, IDDM 7.41, NIDDM 7.41).

Plasma glucose and $\mathrm{HbA}_{1 c}$ concentrations were in the same range in IDDM and NIDDM patients and, as expected, significantly higher than in the nondiabetic control group (Table 3). Hematocrit concentrations were identical for all groups (control individuals and IDDM and NIDDM patients).

2,3-DPG levels were significantly elevated in IDDM patients when compared to the control group, whereas increased levels in NIDDM patients were not statistically significant. ATP concentrations were identical for the three groups (control, IDDM and NIDDM) (Table 3).

\section{Discussion}

Our ODC data for the control individuals $\left(\mathrm{PO}_{2}\right.$ at $50 \%$ saturation $=26.8 \mathrm{mmHg}$; Table 1) closely agree with the extensive list of standard ODC reported for human blood (26.9 mmHg; Ref. 35). As mentioned above, Ditzel's group $(9,11,12)$ suggested that insulin treatment would shift the ODC to the left, reduce oxygen delivery to the systemic tissues and potentially cause tissue necrosis in patients. They suggested that the ODC would undergo a shift to the left due to a combination of formation of glycosylated hemoglobin and a decrease of 2,3-DPG. Further- more, they proposed that tissue damage would develop as a long-term consequence of impaired oxygen delivery. This idea received support from experiments on diabetic rats (13). Our results did not confirm these reports, since the ODC positions were not affected by diabetes mellitus or by insulin treatment. In both groups of diabetic patients, the elevated $(\mathrm{P}<0.05) \mathrm{HbA}_{1 \mathrm{c}}$ fraction could shift the ODC to the left. This effect on the ODC, however, was masked by an elevated $(\mathrm{P}<0.05)$ level of red cell 2,3-DPG in the IDDM group. A tendency to an increase occurred in the NIDDM group but was not statistically significant. Consistently, Roberts et al. (36) reported increased red cell 2,3-DPG concentrations in IDDM patients with elevated $\mathrm{HbA}_{1 \mathrm{c}}$. Moreover, these patients had no symptoms of hypoxic stress. Triolo et al. (37) reported similar data for patients without ketoacidosis. Furthermore,

Table 2. Parameters of the Hill plots and oxygen dissociation curves.

\begin{tabular}{lccc}
\hline & Control & IDDM & NIDDM \\
\hline Correlation coefficient & $>0.99$ & $>0.99$ & $>0.99$ \\
Regression equation & $y=-3.81+2.67 x$ & $y=-3.97+2.76 x$ & $y=-3.97+2.75 x$ \\
$95 \%$ Cl for intercept & $(-3.94$ to -3.67$)$ & $(-4.09$ to -3.85$)$ & $(-4.08$ to -3.85$)$
\end{tabular}

Regression equations for the Hill plot. The slope of the curve is the Hill coefficient. $P_{50}$ is the partial oxygen pressure that saturates $50 \%$ of the hemoglobin. The $P_{50}$ values (see Table 1) and Hill coefficients were not statistically different, since the 95\% confidence intervals $(95 \% \mathrm{Cl})$ of the group overlap (Pearson test). IDDM, insulindependent diabetes mellitus; NIDDM, non-insulin-dependent diabetes mellitus.

Table 3. Comparison of blood variables of the studied groups.

\begin{tabular}{lccc}
\hline Variable & Control & IDDM & NIDDM \\
\hline Glycemia $(\mathrm{mg} / \mathrm{dl})$ & $93.6 \pm 1.7$ & $151.2 \pm 21.0^{*}$ & $160.5 \pm 11.6^{*}$ \\
$\mathrm{HbA}_{1 \mathrm{c}}(\%)$ & $4.6 \pm 0.1$ & $10.5 \pm 0.7^{*}$ & $9.0 \pm 0.4^{*}$ \\
$2,3-\mathrm{DPG}(\mu \mathrm{mol} / \mathrm{ml}$ whole blood) & $2.05 \pm 0.08$ & $2.45 \pm 0.12^{*}$ & $2.21 \pm 0.08$ \\
$\mathrm{pH}$ & $7.40 \pm 0.01$ & $7.36 \pm 0.01^{*}$ & $7.38 \pm 0.01$ \\
$\mathrm{ATP}(\mu \mathrm{mol} / \mathrm{g} \mathrm{Hb})$ & $4.08 \pm 0.11$ & $4.17 \pm 0.15$ & $4.25 \pm 0.12$ \\
$\mathrm{PCO}_{2}(\mathrm{mmHg})$ & $42.3 \pm 1.0$ & $47.2 \pm 2.4$ & $44.1 \pm 2.1$
\end{tabular}

Data are reported as means $\pm \mathrm{SEM}$ ( $\mathrm{n}$-values stated in the text). $\mathrm{PCO}_{2}$ indicates the values prior to tonometry of the blood. $\mathrm{HbA}_{1 \mathrm{c}}=$ glycosylated hemoglobin; 2,3-DPG = 2,3-diphosphoglycerate; IDDM = insulin-dependent diabetes mellitus; $N I D D M=$ noninsulin-dependent diabetes mellitus. ${ }^{*} \mathrm{P}<0.05$ compared to the control group (ANOVA and Student $t$-test). 
Rodriguez et al. (38) reported that diabetic patients with micro- or macroangiopathy had elevated levels of 2,3-DPG. On the other hand, Giardina et al. (39) measured 2,3-DPG concentration in diabetic patients and concluded that the values were equal to those of normal control individuals. A decreased level of red cell ATP plus 2,3-DPG was related to nerve tissue degeneration by Farber et al. (13), studying insulin-treated rats with induced diabetes mellitus. Neither group of patients in our study showed any change in red cell ATP levels due to diabetes mellitus.

The contradictions in the literature are difficult to explain. Results obtained with experimental animals may not apply to human physiology. Even within the framework of human physiology, conflicts may arise from the selection of specific groups for study. Using standard criteria for patient selection, we conclude that neither diabetes nor insulin treatment modified the position of the ODC when comparisons were performed at identical $\mathrm{PCO}_{2} / \mathrm{pH}$. This questions the idea of tissue damage due to an impaired pressure for oxygen delivery to tissues. In particular, it was not possible to confirm an effect of insulin treatment on the ODC.

Information on tissue damage in diabetes mellitus has increased in recent years. Importantly, clinical complications in patients have been related to alterations of taurine metabolism rather than to an altered position of the ODC (for a recent review, see Ref. 40). Therefore, several important tissue damages can be explained without implying any adverse shift to the left of the position of the ODC.

\section{Acknowledgments}

We would like to thank Prof. Dr. Renato Hélio Migliorini for many helpful comments during the course of the project. We also acknowledge the generous attitude of Prof. Dr. R.E. Weber, Department of Zoophysiology, Aarhus University, Aarhus, Denmark, who provided materials that were unavailable in Brazil. Moreover, we are grateful to Dr. Joaquim Coutinho Neto for the use of equipment. We also thank Dr. Roseli Soncini and Elizabete Sobrani for helpful advice.

\section{References}

1. Benesch R \& Benesch RE (1967). The effect of organic phosphates from the human erythrocyte on the allosteric properties of hemoglobin. Biochemical and Biophysical Research Communications, 26: 162-167.

2. Bellingham AJ, Detter JC \& Lenfant C (1970). The role of hemoglobin affinity for oxygen and red-cell 2,3-diphosphoglycerate in the management of diabetic ketoacidosis. Transactions of the Association of American Physicians, 83: 113-120.

3. Lichtman MA, Miller DR \& Waterhouse C (1971). Reduced red cell glycolysis, 2,3-diphosphoglycerate and adenosine triphosphate concentration, and increased hemoglobin-oxygen affinity caused by hypophosphatemia. Annals of Internal Medicine, 74: 562-568.

4. Winslow RM (1984). High-altitude polycythemia. In: West JB \& Lahiri S (Editors), High Altitude and Man. American Physiological Society, Bethesda, MD, 163-173.

5. Thomas HM, Lefrak SS, Irwin RS, Fritts HW \& Caldwell PR (1974). The oxyhemoglobin dissociation curve in health and disease. Role of 2,3-diphosphoglycerate. American Journal of Medicine, 57: 331348.

6. Guest GM \& Rapoport S (1940). Clinical studies of the organic acidsoluble phosphorus of red blood cells in different acidotic states. Journal of Laboratory and Clinical Medicine, 26: 190-198.

7. Alberti KG, Emerson PM, Darley JH \& Hockaday TD (1973). 2,3-
Diphosphoglycerate and tissue oxygenation in uncontrolled diabetes mellitus. Lancet, 2: 391-395.

8. Ditzel J (1973). Effect of plasma inorganic phosphate on tissue oxygenation during recovery from diabetic ketoacidosis. Advances in Experimental Medicine and Biology, 37A: 163-172.

9. Ditzel J \& Standl E (1975). The problem of tissue oxygenation in diabetes mellitus. Acta Medica Scandinavica, 578 (Suppl): 59-68.

10. Marchenko LF, Baturin AA \& Terenteva EA (1991). Diagnostic value of detection of blood levels of lactate, pyruvate and 2,3-diphosphoglycerate in children with diabetes mellitus. Pediatriya, 2: 26-30.

11. Ditzel J, Jaeger $P \&$ Standl E (1978). An adverse effect of insulin on the oxygen release capacity of red blood cells in nonacidotic diabetics. Metabolism, 27: 927-934.

12. Ditzel J (1980). Affinity hypoxia as a pathogenic factor of microangiopathy with particular reference to diabetic retinopathy. Acta Endocrinologica Supplementum, 238: 39-55.

13. Farber SD, Farber MO, Brewer G, Magnes CJ \& Peterson RG (1991). Oxygen affinity of hemoglobin and peripheral nerve degeneration in experimental diabetes. Journal of Neurological Sciences, 101: 204207.

14. Bodnar PN \& Pristupiuk AM (1982). Assessment of the 2,3-diphosphoglycerate content of erythrocytes in diabetes mellitus. Problemy Endokrinologii, 28: 15-17. 
15. Ditzel J (1979). Changes in red cell oxygen release capacity in diabetes mellitus. Federation Proceedings, 38: 2484-2488.

16. Bunn HF (1978). The glycosylation of hemoglobin: relevance to diabetes mellitus. Science, 200: 21-27.

17. MacDonald R (1977). Red cell 2,3-diphosphoglycerate and oxygen affinity. Anaesthesia, 32: 544-553.

18. Bener YN (1988). Consequences of phosphate imbalance. Annual Review of Nutrition, 8: 121-148.

19. Ditzel J (1972). Impaired oxygen release caused by alterations of the metabolism in the erythrocytes in diabetes. Lancet, 1: 721-723.

20. Story CJ, Roberts AP \& Ryall RG (1986). Borderline maintenance of erythrocyte 2,3-diphosphoglycerate concentrations in normoxic type 1 (insulin dependent) diabetic subjects. Clinical Science, 70: 127129.

21. Alder VA, Yu DY, Su EN \& Cringle SJ (1992). Comparison of hematologic parameters in normal and streptozotocin-induced diabetic rats. Laboratory Animal Science, 42: 170-173.

22. Kihara M, Zollman PJ, Smithson IL, Lagerlund TD \& Low PA (1994). Hypoxic effect of exogenous insulin on normal and diabetic peripheral nerve. American Journal of Physiology, 266: E980-E985.

23. Schrumpf JD, Sheps DS, Wolfson S, Aronson AL \& Cohen LS (1977). Altered hemoglobin-oxygen affinity with long-term propranolol therapy in patients with coronary artery disease. American Journal of Cardiology, 40: 76-82.

24. Huchkauf H, Schäfer JH \& Kollo D (1979). Oxygen affinity of haemoglobin and red cell acid-base status in patients with severe chronic obstructive lung disease. Bulletin Europeen de Physiopathologie Respiratoire, 12: 129-145.

25. Juel R (1979). 2,3-Diphosphoglycerate: its role in health and disease. CRC Critical Reviews in Clinical Laboratory Sciences, 10: 113-146.

26. Monti M \& Bucur I (1976). Red cell organic phosphates during administration of salicylates. Scandinavian Journal of Haematology, 16: 295-299.

27. Marengo-Rowe AJ (1965). Rapid electrophoresis and quantitation of hemoglobin on cellulose acetate. Journal of Clinical Pathology, 18: 790-792.

28. Haab PE, Piiper J \& Rahn H (1960). Simple method for rapid determi- nation of an $\mathrm{O}_{2}$ dissociation curve of the blood. Journal of Applied Physiology, 15: 1148-1149.

29. Scheid P \& Meyer M (1978). Mixing technique for study of oxygenhemoglobin equilibrium: a critical evaluation. Journal of Applied Physiology, 45: 818-822.

30. Trinder $P$ (1969). Determination of blood glucose using an oxidaseperoxidase system with a non-carcinogenic chromogen. Journal of Clinical Pathology, 22: 158-161.

31. Lowry OH, Passonneau JV, Hasselberger FX \& Schultz DV (1964). Effect of ischemia on known substrates and cofactors of the glycolytic pathway in brain. Journal of Biological Chemistry, 239: 18-30.

32. Rose ZB \& Liebowitz J (1970). Direct determination of 2,3-diphosphoglycerate. Analytical Biochemistry, 35: 177-180.

33. Bucher T (1989). Commentary on: "Über ein phosphatübertragendes Gärungsferment". Biochimica et Biophysica Acta, 1000: 228-250.

34. Adams HA (1963). Adenosine 5'-triphosphate determination with phosphoglycerate kinase. In: Bergmeyer HU (Editor), Methods of Enzymatic Analysis. Academic Press, New York, 539-543.

35. Reeves RB (1980). The effect of temperature on the oxygen equilibrium curve of human blood. Respiration Physiology, 42: 317-328.

36. Roberts AP, Story CJ \& Ryall RG (1984). Erythrocyte 2,3-biphosphoglycerate concentrations and haemoglobin glycosylation in normoxic type 1 (insulin-dependent) diabetes mellitus. Diabetologia, 26: 389391.

37. Triolo G, Giardina E, Contorno A, Cipolla T, Giannuoli G, Caimi G, Catania A \& Rinaldi A (1981). Glycosylated hemoglobins and erythrocyte 2,3-diphosphoglycerate in diabetes mellitus. Archivio per le Scienze Mediche, 138: 179-185

38. Rodriguez CA, Rodríguez CF, Perez Blanco F, Nuñez CJ \& Mora LRJ (1998). Behavior of 2,3-diphosphoglycerate in diabetes mellitus. Revista Clinica Española, 165: 39-41.

39. Giardina E, Triolo G, Contorno A \& Rinaldi A (1980). Erythrocytic 2-3diphosphoglycerate in diabetes mellitus. Minerva Medica, 71: 17311741.

40. Hansen SH (2001). The role of taurine in diabetes and the development of diabetic complications. Diabetes/Metabolism Research and Reviews, 17: 330-346 